\title{
DA TRAGÉDIA À COMÉDIA: UMA LEITURA DO CONTO "A CARTOMANTE", DE MACHADO DE ASSIS
}

\section{EDER RODRIGUES PEREIRA}

Universidade de São Paulo

São Paulo, São Paulo, Brasil

Resumo: O presente artigo estabelece uma relação comparativista entre o conto "A cartomante", de Machado de Assis, e a tragédia Hamlet, de Shakespeare, utilizando para isso alguns conceitos da poética clássica, da teoria dos gêneros e da estilística. Com isso, observamos o modo como determinados elementos estruturais e temáticos existentes na peça de Shakespeare assumem uma nova dimensão no conto de Machado que, além de realizar um diálogo com a tragédia shakespeariana, reaviva diversas questões de ordem estética e ideológica.

Palavras-chave: tragédia; comédia; inversão

\section{FROM TRAGEDY TO COMEDY: A READING OF THE SHORT STORY "THE FORTUNETELLER", BY MACHADO DE ASSIS}

\begin{abstract}
This paper establishes a comparativist relationship between the short story "The Fortuneteller", by Machado de Assis, and the tragedy, Hamlet, by Shakespeare, using it for some concepts of classical poetics, of gender and style theory. Thus, we observe how certain structural and thematic elements present in the Shakespearian drama take on a new dimension in the story by Machado that besides performing a dialogue with Shakespearean tragedy, revives several aesthetic and ideological issues.
\end{abstract}

Keywords: tragedy; comedy; inversion 


\section{Introdução}

10 cartomante", de Machado de Assis, é um conto geralmente $\triangle$ analisado pelo viés irônico, e essa marca do estilo do autor, que 1 também aparece em outros contos e romances da maturidade, associa-se a uma visão que destaca as contradições da alma humana e do convívio social. Dessa maneira, o autor faz uso constante dessa técnica narrativa, cuja estrutura fundamental consiste em frustrar expectativas, fazendo com que os acontecimentos tomem rumo contrário aos conjecturados pelo leitor. Ademais, deve-se levar em consideração que Machado foi um apaixonado pelo teatro, tendo até mesmo na fase inicial da sua carreira, entre 1859 e 1866, conquistado a admiração da intelectualidade do Rio de Janeiro como crítico teatral, comediógrafo e tradutor de várias peças. Por causa disso, não estranha ver em sua obra diversas referências a dramaturgos e peças importantes, sem falar na semelhança com "certos modos teatrais de armar as cenas, de fazer entrar e sair personagens, de organizar os diálogos e de indicar o cenário das ações ficcionais", como destaca João Roberto Faria. ${ }^{1}$

Narrado em terceira pessoa, o conto focaliza um triângulo amoroso constituído por Vilela, Rita e Camilo, mas vale ressaltar que a ação não se desenvolve de forma linear. O relato dos fatos começa pelo meio, momento no qual Rita e Camilo já são amantes há algum tempo e estão preocupados com a possibilidade de serem descobertos. Por um olhar retrospectivo, o narrador mostra a amizade de infância entre Vilela e Camilo, o casamento de Vilela com Rita, a condição que uniu os três e o adultério. Depois, ele retoma a angústia dos amantes, acentuada por cartas anônimas, exibe o reconforto dado pela cartomante e o desfecho do conto, quando Vilela mata a esposa e o amigo.

Esse fato aparentemente banal tem, no entanto, elementos relacionados à tragédia Hamlet, de Shakespeare, como pretendemos mostrar adiante. Assim, esta leitura se propõe a observar, a partir de uma breve comparação entre Hamlet e "A cartomante", de que modo determinados aspectos estruturais e temáticos existentes na peça aparecem no conto de Machado de Assis, assumindo um jogo de inversões em diversos níveis.

${ }^{1}$ FARIA, Singular ocorrência teatral, p. 161. 


\section{Da tragédia à comédia}

Quando o príncipe Hamlet deixa os estudos na Universidade de Wittenberg e volta para Elsenor, fica entristecido ao ver que sua mãe se casara às pressas com o seu tio Cláudio, que toma posse do trono. O jovem recebe a visita do espectro do rei, que lhe conta como foi morto, sugerindo ainda o adultério da rainha Gertrudes com o irmão do rei. Desse modo, a peça tem uma história não linear, pois o seu início é marcado por uma ação anterior, movimento temporal assimilado por Machado em "A cartomante". Com isso, há nos textos certa similaridade ao levar em consideração as alternâncias narrativas com os avanços e recuos dos fatos ocorridos. Porém, vale perguntar se a ideia de traição e tragédia assume, nas obras, a mesma perspectiva.

Nessa direção, Anatol Rosenfeld expõe que a teoria dos gêneros é complicada pelo fato de os termos "lírico", "épico" e "dramático" serem empregados em duas acepções. Assim, a primeira está associada à estrutura (significado substantivo), enquanto a segunda se refere aos traços estilísticos (significado adjetivo), contudo "toda obra literária de certo gênero conterá, além dos traços estilísticos mais adequados ao gênero em questão, também traços estilísticos mais típicos de outros gêneros", 2 pois não existe pureza de gênero em sentido absoluto. Dessa forma, o significado substantivo (estrutura) da tragédia deve ser buscado na Poética de Aristóteles, que a define como uma forma específica de mimese, cuja representação das ações de homens de caráter elevado, expressa por uma linguagem ornada, por meio do diálogo e do espetáculo cênico, objetiva a purificação das emoções na medida em que desperta o temor e a piedade no espectador. Trata-se então da "representação duma ação grave, de alguma extensão e completa, em linguagem exornada, cada parte com o seu atavio adequado, com atores agindo, não narrando, a qual, inspirando pena e temor, opera a catarse própria dessas emoções". 3

Assim, observa-se que em Hamlet a representação das ações desses seres elevados visualiza indivíduos socialmente diferenciados, aristocratas e fidalgos, cuja gravidade dos atos abrange não apenas a vida privada, mas também a vida pública. Cláudio mata o irmão, assume o trono e casa-se com a rainha Gertrudes. Um "caso de adultério" e um golpe de Estado, circunscrito

\footnotetext{
${ }^{2}$ ROSENFELD, Gêneros e traços estilísticos, p. 18.

${ }^{3}$ ARISTÓTELES, Poética, p. 24.
} 
em uma esfera complexa de relações (individuais e sociais). Isso ganha proporções maiores no momento em que o espectro do rei aparece, contando os detalhes da morte:

Espectro - [...] Escuta, pois, Hamlet: está sendo anunciado que, estando adormecido em meu pomar, fui mordido por uma serpente; deste modo foram grosseiramente enganados os ouvidos da Dinamarca com esta fabulosa história de meu falecimento; mas tu sabes, nobre jovem, que a serpente que tirou a vida de teu pai usa agora a coroa que lhe pertencia.

Hamlet - Ó minha alma profética! Meu tio!

Espectro - Sim, essa besta incestuosa e adúltera, com o feitiço de seu engenho, com pérfidas dádivas (oh! maldito engenho e malditas dádivas que possuem tal poder de sedução!) conquistou para sua vergonha lascívia a vontade daquela que parecia minha rainha virtuosa!... ${ }^{4}$

Os temas traição, triângulo amoroso, público e privado, presentes na tragédia shakespeariana, são, portanto, levados para "A cartomante", mas as personagens passam a ser representadas por rebaixamentos que contrastam com a citação elevada que abre o conto. Nesse sentido, Machado coloca Vilela, Rita e Camilo numa esfera de inferioridade ou próximo do que Aristóteles afirma sobre a comédia, uma imitação da ação de homens inferiores; "não, porém, com relação a todo vício, mas sim por ser o cômico uma espécie do feio". 5

No conto, Vilela seguiu a carreira de magistrado e, ao voltar da província, onde se casara, abandonou a magistratura e montou banca de advogado. Com situação econômica, social e cultural elevadas, ele é o único personagem apresentado pelo sobrenome e seus rótulos sociais (ex-magistrado e advogado). Sua idade é de vinte e nove anos, e porte grave, ou seja, sério, o que o fazia parecer mais velho do que a mulher.

Em oposição a ele, "Camilo era um ingênuo na vida moral e prática. Faltava-lhe tanto a ação do tempo, como os óculos de cristal, que a natureza põe no berço de alguns para adiantar os anos. Nem experiência. Nem

\footnotetext{
${ }^{4}$ SHAKESPEARE, Hamlet, p. 222-223.

${ }^{5}$ ARISTÓTELES, cit., p. 23-24.
} 
intuição". ${ }^{6} \mathrm{O}$ pai queria que ele fosse médico, mas, com sua morte, Camilo preferiu não ser nada e apenas entrou para o funcionalismo público porque a mãe lhe arranjou o emprego. Desse modo, o narrador antecipa um elemento fundamental da personalidade do personagem, "sem intuição" ele é facilmente levado pelas considerações alheias: a do pai, a da mãe, a de Rita, a da cartomante e, por fim, pelo bilhete de Vilela.

Por sua vez, Rita é caracterizada como uma moça formosa e tonta, "graciosa e viva nos gestos, olhos cálidos, boca fina e interrogativa". ${ }^{7}$ Com a convivência dos três e após a morte da mãe de Camilo, Rita cuidou principalmente do coração dele; "era a sua enfermeira moral". Passam a ler os mesmos livros, ir a passeios e ao teatro juntos, ele lhe ensina damas e xadrez, e ela passa a procurá-lo com "os olhos teimosos". Cercado por Rita, "Camilo quis sinceramente fugir, mas já não pôde. Rita, como uma serpente, foi acercando dele, envolveu-o todo, fez-lhe estalar os ossos num espasmo, e pingou-lhe o veneno na boca". ${ }^{8}$

Assim, aquela imagem da serpente usada pelo espectro do rei para caracterizar Cláudio como um traidor, que aproveita um momento de descanso para derramar nos ouvidos o veneno, é retomada por Machado, mas Rita se transforma nessa serpente cujo veneno é sua própria sedução que atordoa e subjuga Camilo. Ainda, se forçarmos um pouco os ouvidos, todos os atributos da "moça tonta" sugerem essa relação metafórica na medida em que as consoantes constritivas fricativas alveolares /s/ e /z/, a consoante constritiva fricativa labiodental /f/ e a consoante constritiva fricativa palatal /ts/ em "Realmente, graciosa e viva nos gestos, olhos cálidos, boca fina e interrogativa" ou "olhos teimosos" transmitem uma expressividade sonora que lembra o silvar de uma serpente, pois "as consoantes constritivas, pelo seu caráter contínuo, sugerem sons de certa duração, bem como as coisas e fenômenos que os produzem". 9

Ademais, a sintaxe dos períodos, marcada pelas pausas das vírgulas, mostra-se de forma sinuosa quase que rastejando ao ser pronunciada, o que reforça a ideia de que "a seleção e ordem específicas dos fonemas determina

\footnotetext{
${ }^{6}$ ASSIS, A cartomante, p. 256.

${ }^{7}$ Idem, p. 256.

${ }^{8}$ Idem, p. 257.

${ }^{9}$ MARTINS, Introdução à estilística, p. 256.
} 
as qualidades rítmicas da oração e do texto, impondo certos "imperativos" ao eventual recitador e mesmo ao leitor", ${ }^{10}$ aspecto ilustrado a seguir:

Camilo quis sinceramente fugir, / mas já não pôde. / Rita, / como uma serpente, / foi acercando dele, / envolveu-o todo, / fez-lhe estalar os ossos num espasmo, / e pingou-lhe o veneno na boca.

Assim, com uma dimensão quase "naturalista", as personagens são regidas por um movimento de ação - Rita (o animal caçador) - e de inércia Camilo (a presa caçada) -, aspecto que possibilita visualizar certos níveis de significação e estabelecer algumas aproximações e distanciamentos entre os dois textos. ${ }^{11}$ Mas vale observar ainda como a subversão do modelo e de certas motivações aparece em outras partes do conto.

\section{O elevado e o rebaixado, o ser e o parecer}

Uma característica central do conto "A cartomante" ocorre pela oscilação entre elementos que parecem ser o que são e ao mesmo tempo não são o que parecem. Em relação a isso, percebe-se claramente um jogo de oposições ou um complexo esquema de contrastes entre o sério e o cômico, o alto e o baixo, o elevado e o vulgar que é anunciado em vários momentos da narrativa. De acordo com Maria Augusta Fonseca, isso faz parte:

[...] de um quadro mais amplo de dissimulações e traições, avivado pelo aparato de forças adversas que sustenta o conto. Assim, o problema metafísico que Machado extrai do drama de Shakespeare para colocar o relato em movimento não serve apenas para zombar da personagem feminina e para tornar risível o casal de amantes burgueses. Em outro

\footnotetext{
${ }^{10}$ ROSENFELD, Estrutura e problemas da obra literária, p. 56.

${ }^{11}$ No texto em inglês encontra-se a expressão serpente, porém não se pode afirmar que o processo expressivo explorado em português apresenta a mesma dimensão aqui observada. O trecho no original será apresentado para uma comparação dos leitores:

Ghost: I find thee apt - Now, Hamlet, hear:/ "This given out that, sleeping in my orchard./ A serpent stung me; so the whole ear of Denmark/Is by a forged process of my death/Rankly abused: but know, thou noble youth,/ The serpent, that did sting thy father's life,/ Now wears his crown." (SHAKESPEARE, Hamlet, p. 17).
} 
contexto, as personagens trazidas por rebaixamentos (em especial, Rita) estão sintonizadas com matrizes da velha comédia de costumes... ${ }^{12}$

Ademais, essas dissimulações que giram na relação entre Ser versus Parecer mantêm um contato direto com elementos da peça e reforçam as antinomias existentes no conto. Porém, há uma inversão significativa, ou seja, em Hamlet, os fatos que parecem mentiras acabam sendo verdades, enquanto em "A cartomante" os que parecem verdades são mentiras.

O exemplo disso é quando Marcelo e Bernardo mostram a Horácio o espectro do rei que andava assombrando o castelo em determinado horário e local específico. Isso o faz acreditar nos boatos sobre o fantasma e avisar ao amigo Hamlet. O jovem príncipe, então, começa a associar alguns fatos e a suspeitar de alguma traição, visto que a rainha Gertrudes se casa com Cláudio dois meses após o falecimento do rei.

Além disso, o que chama a atenção de Hamlet é o fato de o espectro do rei estar vestido em armas como se fosse para alguma batalha. Contudo, a busca pela verdade não se constrói na peça pelos elementos que estão nessa esfera do parecer, pois mesmo diante do relato do espectro algumas dúvidas ainda permanecem. Para ter certeza dos atos de seu tio, Hamlet resolve surpreendê-lo, fazendo que uma companhia de atores itinerantes represente uma peça contendo episódios da história contada pelo fantasma do pai. E ao ser apresentada, Cláudio fica perturbado e abandona a sala do espetáculo, confirmando as hipóteses de Hamlet.

Desse modo, com uma peça dentro da peça, a verdade é alcançada, cabendo ao príncipe se vingar e restabelecer a ordem. Ao mesmo tempo existe no texto uma consciência de que a própria arte pode servir para buscar a verdade, uma vez que a intenção da peça pedida por Hamlet aos atores é a de provocar em Cláudio a purgação de seus sentimentos. Logo, é possível visualizar por meio de procedimentos metalinguísticos uma reflexão sobre os conceitos aristotélicos de catarse. Conforme Aristóteles, essa sequência de fatos pode ser encaixada na definição de peripécia, porque há uma súbita mutação dos sucessos para o contrário, dando a inversão no nível fabular.

Com o reconhecimento desse contrário, a revelação (anagnorisis), portanto, "constitui a essência do enredo trágico e tem uma finalidade psicagógica, pois suscita nos espectadores os sentimentos de terror e de

12 FONSECA, A cartomante: ciladas do conto, p. 190-191. 
piedade: terror, pela ação nefanda cometida, e piedade, pelo homem que, vítima do destino, é levado a perpetrar um ato infame com a intenção de fazer uma obra de bem". ${ }^{13}$

Já em "A cartomante", os elementos abstratos são elevados ao nível de verdade, e um exemplo bem claro está na indefinição do discurso da adivinha, que se constrói pela utilização de artigos ou pronomes indefinidos para extrair confissões e despejar as palavras desejadas aos clientes, como ocorre em: "A senhora gosta de uma pessoa", "o senhor tem um grande susto", "e quer saber se lhe acontecerá alguma coisa ou não".

Esse recurso, no entanto, esconde algo anterior, visto que, muito mais do que uma adivinhadora do futuro, a personagem é uma mistificadora e ardilosa leitora de gestos. O primeiro contato dela ocorre mediante o relato de Rita, que afirma que a senhora adivinhou o motivo da consulta e tirou as dúvidas e seus temores. Porém, dizer a uma bela moça que o motivo da consulta é uma paixão parece algo bem óbvio. Com isso, é lógico para Rita acreditar no poder da adivinha, porque se a cartomante consegue prever o presente, também será competente para adivinhar o futuro. Dessa maneira, Camilo segue a mesma linha de raciocínio, não percebendo que os fatos foram deduzidos e extraídos da perturbação dele.

Desse modo, os amantes tomam por verdade elementos que não apresentam nenhuma consistência e, mesmo diante de uma sequência de cartas anônimas anunciando a descoberta da relação, ignoram fatos concretos em razão dos abstratos. Assim, a morte de Rita e Camilo mesmo sendo violenta e tão abrupta, sem falar no fato de que não há nela glória nenhuma, serviria talvez para uma manchete em alguma página policial do dia seguinte.

Se, portanto, determinados conceitos da tragédia acabam por ser visualizados em Hamlet, observa-se que em "A cartomante" esses elementos não podem ser encontrados, pois o conto inverte tais efeitos estéticos, como anunciado anteriormente, chegando até mesmo a se aproximar do cômico.

Essa relação da construção da verdade nos textos se dá pela voz de seres elevados e rebaixados, porém tanto um como outro (espectro do rei e a cartomante) giram no plano do insólito, dando a Hamlet ou a Rita e Camilo a liberdade de seguir a mensagem dos "oráculos". Isso, então, sugere que o homem moderno é livre para menosprezar as mitologias e as teologias,

${ }^{13}$ D'ONOFRIO, Teoria do texto, p. 139. 
contudo isso "não o impedirá de continuar a se alimentar dos mitos decadentes e das imagens degradadas", como mostra Mircea Eliade. ${ }^{14}$ Mas até que ponto essas liberdades não refletem também situações ligadas às características de cada texto e às realidades sociais que buscam representar?

\section{Desfechos}

Por fim, de um lado, a peça Hamlet coloca por meio de um drama a história que é ao mesmo instante um crime familiar e de Estado, sem falar que a ação se desenvolve em um espaço em que havia algo de podre. Cabe, então, ao jovem príncipe lutar contra os jogos de interesses e restaurar a ordem perdida. De outro lado, uma vez que em "A cartomante",

os holofotes estão voltados para a ociosidade da vida burguesa na corte imperial, para relações da intimidade e para o motivo da dissimulação e do ocultamento (que o narrador costura com astúcia), não seria demais pensar o conto como sumo evocativo da realidade externa, desdobrada nos procedimentos de narrar, permitindo elos entre tragédias, com diferença de grau. ${ }^{15}$

Assim, ao observar essa rede de perversidade e dissimulação existente na peça, Machado acaba por extrair dela e expor pela arte do conto a fraqueza de espírito e a alienação de personagens diante da vida, mostrando até mesmo as tessituras que movem a sociedade e os homens de seu tempo e de seu país. Contudo, é preciso advertir que a representação das ações na peça de Shakespeare mantém laços com matrizes da tragédia clássica, mesmo que inserida em uma época e em uma sociedade que já partem para uma transformação dos modelos de representação artística.

Por causa disso, surge uma antinomia que permite problematizar historicamente essa forma poética, levando Peter Szondi, em Teoria do drama moderno, a tentar explicar as diversas formas da dramática moderna a partir da resolução dessas contradições que advêm desde Aristóteles. Talvez uma das contradições que nos sirva de reflexão aqui é o fato de que há uma mudança na maneira de representação da existência humana, pois em Hamlet

${ }^{14}$ ELIADE, Imagens e símbolos, p. 7.

${ }^{15}$ FONSECA, cit., p. 210. 
o objetivo é restaurar a ordem, a honra e o equilíbrio no reino da Dinamarca, enquanto em "A cartomante" a ordem, a honra e o equilíbrio beneficiam apenas a personagem Vilela, que defende seus interesses e sua condição de classe com a morte de Rita e Camilo. Não seria isso uma das formas de consolidação da passagem do coletivo ao individual, registrada por meio de um texto literário, que se torna, assim, um documento da história da humanidade?

Uma comparação mais aprofundada sobre as relações de classe existentes nos dois textos, contudo, talvez apresente um direcionamento para a resolução dessa questão. Inicialmente, seria possível pensar, levando-se em consideração a ideia de Georg Lukács, em A teoria do romance, que a forma romanesca é "a imagem espetacular de um mundo que saiu dos trilhos", ${ }^{16}$ o que levaria, de alguma forma, Machado de Assis a trabalhar nesse conto (não uma forma romanesca, mas narrativa) com tantas inversões. Por outro lado, as várias reflexões desenvolvidas por Roberto Schwarz em Um mestre na periferia no capitalismo e Ao vencedor as batatas também explicam tais inversões, além de darem conta de forma aprofundada das questões ideológicas.

Não podemos, no entanto, desconsiderar que os movimentos de inversão existentes em "A cartomante" evidenciam um diálogo com um universo elevado que não pode ser mais representado a não ser por um contraponto cômico, como se indicou brevemente. O que sobra da sociedade e dos homens inseridos nesse contexto são valores que, se comparados aos antigos modelos, só podem ser traduzidos por rebaixamentos e por ironias, pois o predominante são forças ideológicas aliadas para a manutenção do que há de mais podre na "Dinamarca abrasileirada".

Rita e Camilo fazem parte da galeria dos personagens da literatura brasileira que subvertem a ordem estabelecida ou defendida pela classe dominante, para os quais o único fim só pode ser a morte. Porém, se tal recurso era comum nas narrativas românticas, no conto torna-se numa maneira de rir de algo que só pode ser classificado como patético. As feições do trágico são invertidas e transformadas em uma comédia burguesa, mas ao provocar a "maiêutica", o surgimento das ideias, Machado mostra que há mais mistérios em "A cartomante" do que talvez possa imaginar esta leitura, na medida em

${ }^{16}$ LUKÁCS, Teoria do romance, p. 14. 
que reaviva várias questões de ordem estética e ideológica, além de nos fazer perceber a não superação histórica de alguns modelos.

\section{Referências}

ARISTÓTELES. A poética clássica. São Paulo: Cultrix, 2005.

ASSIS, Machado de. A cartomante. Contos/Uma antologia. São Paulo: Companhia das Letras, 1998, p. 256-257.

D'ONOFRIO, Salvatore. Teoria do texto. 2. ed. São Paulo: Ática, 1999.

ELIADE, Mircea. Imagens e símbolos. São Paulo: Martins Fontes, 2002.

FARIA, João Roberto. Singular ocorrência teatral. Revista USP, São Paulo, n. 10, p. 161-166, 1991.

FONSECA, Maria Augusta. A cartomante: ciladas do conto. In: FANTINI, Marli (org.). Crônicas da antiga corte: Literatura e memória em Machado de Assis. Belo Horizonte: Ed. UFMG, 2008, p. 185-214.

MARTINS, Nilce Sant'anna. Introdução à estilística. São Paulo: T. A. Queiroz, 1997.

ROSENFELD, Anatol. Estrutura e problemas da obra literária. São Paulo: Perspectiva, 1976.

—. Gêneros e traços estilísticos. In:___ O teatro épico. São Paulo: Perspectiva, 2004.

SCHWARZ, Roberto. Um mestre na periferia do capitalismo: Machado de Assis. São Paulo: Duas Cidades, 2000.

Ao vencedor as batatas. Forma literária e processo social nos inícios do romance brasileiro. São Paulo: Duas Cidades, 2000.

SHAKESPEARE, William. Hamlet: O Príncipe da Dinamarca. São Paulo: Abril, 1978.

Hamlet. London: Orberg's Edition, 1818.

SZONDI, Peter. Teoria do drama moderno. São Paulo: Cosac Naify, 2001.

EDER RODRIGUES PEREIRA é doutor em Teoria Literária e Literatura Comparada pela Faculdade de Filosofia, Letras e Ciências Humanas da Universidade de São Paulo (2015). Possui mestrado em Teoria Literária e Literatura Comparada (2009) e graduação em LetrasPortuguês (2004) pela mesma instituição. Atualmente, desenvolve projeto de pesquisa de pós-doutorado no IEB-USP, com supervisão da Profa. Dra. Telê Ancona Lopez, sobre o romance Noite profunda/Os espelhos, obra inédita de Osman Lins. E-mail: ederrodriguespereira@yahoo.com.br. 